American Journal of Applied Sciences 5 (10): 1313-1317, 2008

ISSN 1546-9239

(C) 2008 Science Publications

\title{
Validation of the Calculation and Measurement Techniques of Earth Resistance Values
}

\author{
N. Mohamad Nor, R. Rajab and K. Ramar \\ Faculty of Engineering, Multimedia University, Malaysia
}

\begin{abstract}
Much research has been published in the literature on the mathematical approaches to obtain the most accurate earth resistance and resistivity values. However, the published research only conducted the comparisons among the mathematical/computational techniques and so far none has conducted validation tests of these mathematical/computational methods against the real earth resistance measurement at real field sites. Thus, the main contribution of this research is to show the validity of the formulas available in the literature against the measured earth resistance value at field site. The earth resistance values at three field sites for the earthing systems consists of two, three and four rods were obtained with i) calculation, where the earth resistivity is first measured, which later interpreted into 2 layers earth and used to calculate for the earth resistance and ii) measurements using a Fall-of-Potential Method. The results from this present study can help to validate the mathematical approaches in some published work against the measurement results. Also, this is the first time this kind of comparison study between the calculated and measured for two layers soil model is presented, which can help to improve the earth resistance formulas in a future, since the calculation of earth resistance is important especially at the preliminary earthing system designs.
\end{abstract}

Key words: Earthing systems, earth resistivity, fall-of-potential method, earth resistance values, twolayers earth

\section{INTRODUCTION}

In general many standards proposed the maximum earth resistance value of $10 \Omega$. In practice, it is always challenging to obtain the required earth resistance value due to a greater use of high-voltage underground cables where the protective metallic outer sheath is insulated from the ground by a PVC outer layer instead of semi conductive jute, increasing limitations on the allocation of the ground area, sites which exhibit non-uniform soil conditions, close proximity of third party equipment, particularly telecommunications and housing and a trend towards higher fault currents due to power system integration.

It is important to obtain the soil resistivity field data and interpret it accurately, so that the right size/configuration of earth electrode can be determined in order to achieve the required earth resistance values. In this study, three field sites are selected for the purpose of this study and the soil resistivity data of two layers were obtained. For each site, three types of earth configurations are investigated, 2, 3 and 4 rods. The calculated earth resistance values for each earthing system are then compared with that of measured value. Close results were obtained between the measured and calculated earth resistance values. The study has shown that the 2-layers soil interpretation and the earth resistance formulas developed in the literature may be enough for the calculation of earth resistance values.

\section{FIELD DATA}

The first step that needs to be conducted in designing the earthing systems is, to measure the soil resistivity. In this study, the Wenner Method as outlined in the standards namely ANSI/IEEE Std. $80-2000^{[8]}$ edition, IEEE Std $81^{[9]}$, ANSI/IEEE Std 142-1991 ${ }^{[10]}$, is used for the resistivity measurements at three field sites.

In this method, the electrodes are buried in four small holes in the earth, all at depth b and spaced (in a straight line) at intervals a. A test current $\mathrm{I}$ is passed between the two outer electrodes and the potential V between the two inner electrodes is measured with a potentiometer or high-impedance voltmeter (Fig. 1). Then V/I gives the resistance $\mathrm{R}$ in ohms, where the resistivity value can be determined from Eq. (1)

$$
\rho=2 \pi \mathrm{aR}
$$

where, $\rho$ is the soil resistivity and a is the probe spacing. 


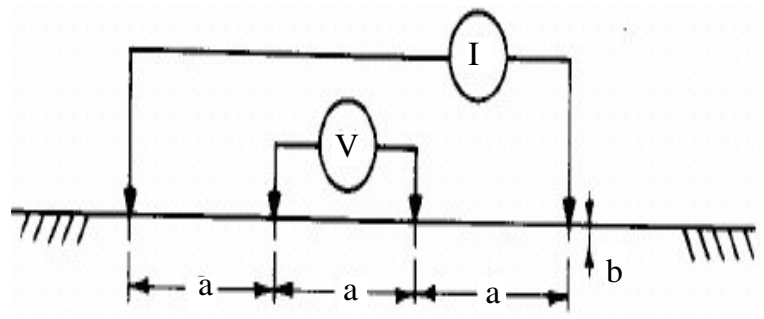

Fig. 1: Wenner method test circuit arrangement

Table 1: Apparent soil resistivity values, $\rho_{\mathrm{a}}$ for different sites

\begin{tabular}{llll}
\hline & Apparent resistivity $(\Omega \mathrm{m})$ & \\
Probe & --------- & Site 3 \\
spacing $(\mathrm{m})$ & Site 1 & Site 2 & 636.6 \\
\hline 0.5 & 473.8 & 812.1 & 683.7 \\
0.7 & 455.7 & 756.1 & 651.6 \\
1 & 377.0 & 711.6 & 613.4 \\
1.25 & 305.5 & 648.0 & 597.1 \\
1.5 & 263 & 557.9 & 492.0 \\
2 & 202.3 & 493.9 & 452.0 \\
2.5 & 160.8 & 397.4 & 407.6 \\
3 & 140.4 & 338.3 & 366.7 \\
3.5 & 132.2 & 294.7 & 343.9 \\
4 & 128.2 & 257.6 & 335.0 \\
5 & 119.4 & 218.3 & \\
\hline
\end{tabular}

A set of readings taken with various probe spacings gives a set of resistivities. In this study, for each site, the soil resistivity measurements are conducted at least twice to double check the measurements. Table 1 shows the measured apparent soil resistivity values obtained for all these three sites. The soil resistivity values obtained from these measurements are then interpreted into two-layer soil using the master curves $^{[7]}$ and Genetic Algorithm (GA) ${ }^{[3]}$.

\section{SOIL RESISTIVITY INTERPRETATION}

As has been generally known, the interpretation of the results obtained in the field is perhaps the most difficult part, because the earth resistivity variation is great and complex. Much research ${ }^{[3,7]}$ has conducted the study on the interpretation of two distinct soil resistivity layers. IEEE Std $81-1983^{[9]}$ also stated that for applications in power engineering, the two-layer equivalent model is accurate enough without being mathematically too involved. Thus, in this present study, the soil resistivity data is interpreted into two layers of soil, using the master resistivity curves ${ }^{[7]}$ and Genetic Algorithm (GA) ${ }^{[3]}$. For the purpose of a better understanding on the soil interpretation methods, some details are included in the respective research.

Master resistivity curves: The resistivity values of 3 sites are plotted against the electrode spacing. Each

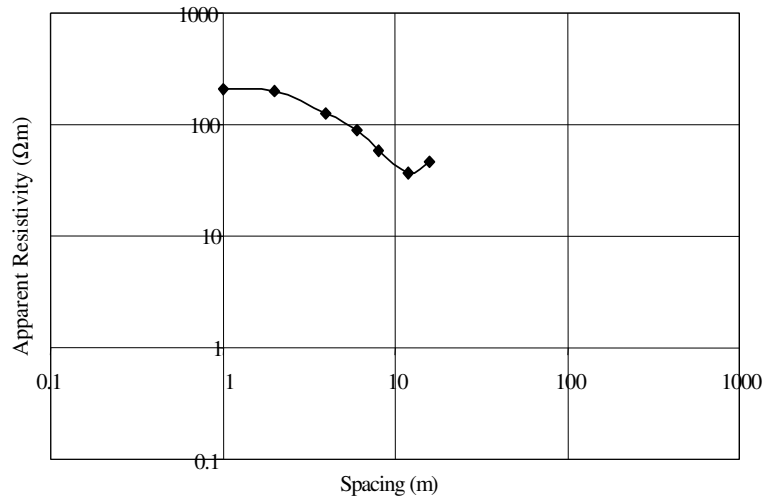

Fig. 2: Measured soil resistivity curve

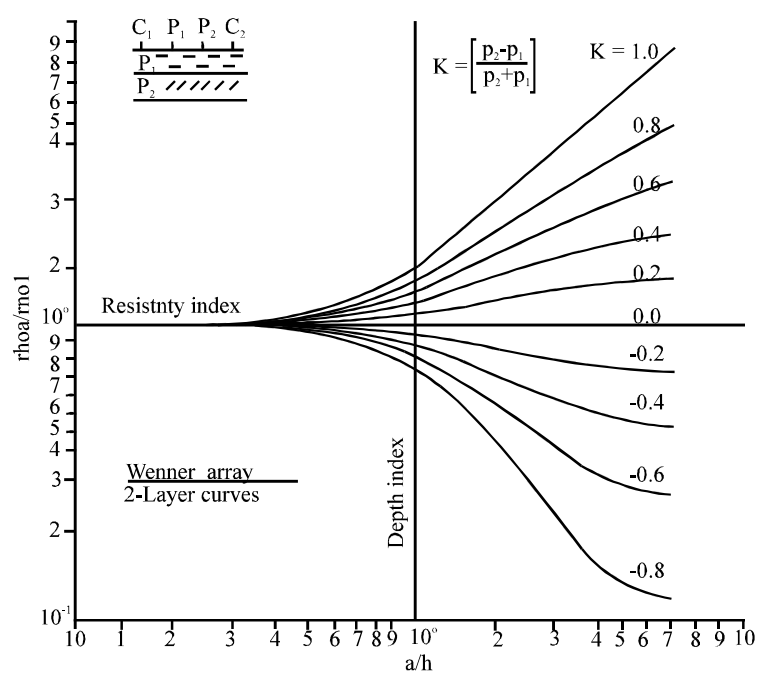

Fig. 3: Theoretical master curves for the wenner array (reproduced from ${ }^{[7]}$ )

result is analysed using the Master Curves, where the upper resistivity, $\rho_{1}$, lower resistivity $\rho_{2}$ and thickness of the first layer, $h$ obtained at 3 sites using the master curves are obtained. Figure 2 shows a graph of the apparent resistivity $\rho_{a}$ of one site, plotted against the spacing a on a logarithmic scale with the same modulus as the master curves. Figure 2 is then compared with a set of theoretical master curves (Fig. 3), computed and produced by Orellana and Mooney ${ }^{[7]}$. The individual curves are described in terms of a reflection coefficient $\mathrm{K}$ given by:

$$
K=\frac{\rho_{2}-\rho_{1}}{\rho_{2}+\rho_{1}}
$$

The interpretation of a two layer apparent resistivity graph can be done by superposing Fig. 2 and 
then shifting it over the master curves of Fig. 3, keeping the coordinate axes parallel, until a reasonable match is obtained with one of the master curves or with an interpolated curve.

There are also resistivity data available in the booklet $^{[7]}$, which make up for the master curves. From the analysis, the values of the three parameters (upper resistivity, $\rho_{1}$, lower resistivity $\rho_{2}$ and thickness of the first layer, $\mathrm{h}$ are obtained for 3 field sites.

Genetic Algorithm (GA): The method and formulas adopted in this present study is taken from the remarkable work by Gonos and Stathopulos ${ }^{[3]}$.

In this method, the calculation of the parameters of a two-layer structure of the earth is an optimization problem. For the computation of the three parameters (soil resistivity of both layers and thickness of the upper layer), the minimization of the function $\mathrm{F}_{\mathrm{g}}$ is necessary;

$$
F_{g}=\sum_{i=1}^{N} \frac{\left|\rho_{\alpha i}^{m}-\rho_{\alpha i}^{c}\right|}{\rho_{\alpha i}^{m}}
$$

where, $\rho_{\alpha \mathrm{i}}^{\mathrm{m}}$ is the $\mathrm{i}^{\text {th }}$ measurement of the soil resistivity when the distance between two sequential probes is $\alpha \mathrm{i}$, while $\rho_{\alpha \mathrm{i}}^{\mathrm{c}}$ is the computed value of the soil resistivity for the same distance. The soil resistivity is calculated using equations below;

$$
\rho_{\alpha}^{\mathrm{c}}=\rho_{\mathrm{i}}\left(1+4 \sum_{\mathrm{n}} \mathrm{K}^{\mathrm{n}}\left(\frac{1}{\sqrt{\mathrm{A}}}-\frac{1}{\sqrt{\mathrm{B}}}\right)\right)
$$

where, $\mathrm{n}=1 \ldots \infty, \mathrm{K}$ is the reflection coeficient, as in Eq. (1) and

$$
\mathrm{A}=1+\left(\frac{2 \mathrm{nh}}{\mathrm{a}}\right)^{2}
$$

where, $\mathrm{B}=\mathrm{A}+3$

The soil resistivity values interpreted using the master curves ${ }^{[7]}$, together with the $\mathrm{GA}^{[3]}$ are shown in Table 2.

Based on the resistivity values obtained from the master curves and GA, the earth resistance values are calculated for the earthing systems consist of simple configurations i.e., 2, 3 and 4 rods.

\section{CONSTRUCTION OF EARTH GRID}

In this study, for each site, simple earthing systems configurations consist of 2,3 and 4 rods with a diameter of $1 \mathrm{~cm}$ and with the separation distance from

\begin{tabular}{|c|c|c|c|}
\hline \multicolumn{2}{|l|}{$\overline{\text { Site 1 }}$} & Master curves $^{[8]}$ & $(\mathrm{GA})^{[5]}$ \\
\hline \multicolumn{4}{|c|}{ Site 1} \\
\hline \multicolumn{2}{|c|}{ Upper resistivity, $\rho_{1}(\Omega \mathrm{m})$} & 540 & 525.6 \\
\hline \multicolumn{2}{|c|}{ Lower resistivity, $\rho_{2}(\Omega \mathrm{m})$} & 108.25 & 112.5 \\
\hline \multicolumn{2}{|l|}{ Thickness, h (m) } & 0.8 & 0.83 \\
\hline \multicolumn{4}{|l|}{ Site 2} \\
\hline \multicolumn{2}{|c|}{ Upper resistivity, $\rho_{1}(\Omega \mathrm{m})$} & 780 & 806.4 \\
\hline \multicolumn{2}{|c|}{ Lower resistivity, $\rho_{2}(\Omega \mathrm{m})$} & 195 & 180.8 \\
\hline \multicolumn{2}{|l|}{ Thickness, h (m) } & 1.3 & 1.34 \\
\hline \multicolumn{4}{|l|}{ Site 3} \\
\hline \multicolumn{2}{|c|}{ Upper resistivity, $\rho_{1}(\Omega \mathrm{m})$} & 720 & 709.4 \\
\hline \multicolumn{2}{|c|}{ Lower resistivity, $\rho_{2}(\Omega \mathrm{m})$} & 288.4 & 290.6 \\
\hline \multicolumn{2}{|c|}{ Thickness, h (m) } & 1.25 & 1.3 \\
\hline \multirow{2}{*}{ Configurations } & \multicolumn{2}{|l|}{ Calculated } & able 3: Calculated earth resistance values \\
\hline & $\begin{array}{l}\mathrm{R}_{\text {calc }}(\Omega) \text { where } \\
\text { the resistivity } \\
\text { values are } \\
\text { obtained } \\
\text { from GA }\end{array}$ & $\begin{array}{l}\mathrm{R}_{\text {calc }}(\Omega) \text { where } \\
\text { the resistivity } \\
\text { values are } \\
\text { obtained from } \\
\text { master curves }\end{array}$ & Measured \\
\hline \multicolumn{4}{|l|}{ Site 1} \\
\hline & 53.6 & 51.08 & 49.1 \\
\hline & 40.1 & 38.22 & 36.6 \\
\hline & 32.3 & 30.74 & 29.4 \\
\hline & 126.34 & 126.2 & 122.23 \\
\hline \multirow{2}{*}{$0^{\circ} 0$} & 94.58 & 94.57 & 95.27 \\
\hline & 76.2 & 76.23 & 72.67 \\
\hline & 153.4 & 149.03 & 151 \\
\hline & 115.67 & 112.39 & 121.3 \\
\hline$\bigcirc$ & 93.55 & 90.89 & 95.73 \\
\hline
\end{tabular}

Table 2: Soil resistivity values Interpreted using the Master Curves and GA into two layers of soil

each other of $2 \mathrm{~m}$ are used. All of the earth rods are buried at the depth of $1.8 \mathrm{~m}$ for all cases.

Table 3 shows the arrangement for the earth electrodes consisting of 2, 3 and 4 rods. All of these copper rods are all connected with wires to ensure its connectivity.

\section{EARTH RESISTANCE CALCULATION}

There are many analytical methods and formulas of earth resistances have been proposed in the literature, Dwight ${ }^{[5]}$ listed the earth resistance formula for one- 
layer, Nahman and Djordjevic ${ }^{[1]}$ and Chow et al. ${ }^{[2]}$ listed the earth resistance for two layers of soil, Gonos and Stathopulos ${ }^{[3]}$ and Dawalibi and Blattner ${ }^{[4]}$ for multi-layer of earth. In this present research, the resistance value is obtained using the formulas from Chow et $a l .{ }^{[2]}$ for the two layers soil. The resistivity values are obtained from the methods described in Section 3.

Chow et al. ${ }^{[2]}$ presented a number of formulas for a two-layered earth, from a single driven rod to the rodbed connected to a grid.

The earth resistance formulas for all the rods where the rods penetrate the lower layer are given by;

$$
\begin{gathered}
\mathrm{R}_{\mathrm{t}}=\frac{1}{\frac{1}{\mathrm{R}_{\mathrm{a}}}+\frac{1}{\mathrm{R}_{\mathrm{b}}}} \\
\mathrm{R}_{\mathrm{a}}=\frac{\rho_{2}}{\left(1+\mathrm{h}_{\mathrm{o}}-\mathrm{h}\right)} \mathrm{g}_{\mathrm{o}} \frac{\mathrm{F}_{\mathrm{o}}}{\mathrm{N}_{\mathrm{o}}} \\
\mathrm{R}_{\mathrm{b}}=\frac{\rho_{1}}{\left(\mathrm{~h}-\mathrm{h}_{\mathrm{o}}\right)} \mathrm{g}_{\mathrm{o}} \frac{\mathrm{F}_{\mathrm{o}}}{\mathrm{N}_{\mathrm{o}}}+\frac{\rho_{1}}{\mathrm{~h}} \phi_{\mathrm{o}}
\end{gathered}
$$

where, it is given in Chow et al. ${ }^{[2]}$ that for the rodbed in two-layers earth,

$$
\begin{gathered}
\mathrm{g}_{0}=\frac{1}{2 \pi}\left[\ln \left(\frac{2 \mathrm{~L}_{\mathrm{R}}}{\mathrm{d} / 2}\right)-1+\frac{\ln 2}{1+\frac{(4 \ln 2) \mathrm{h}}{\mathrm{L}_{\mathrm{R}}}}\right] \\
\mathrm{F}=1+\left(\mathrm{N}_{0}-\frac{1}{\sqrt{\mathrm{N}_{0}}}\right) \frac{\mathrm{R}_{\mathrm{s}}}{\mathrm{R}_{\mathrm{l}}}
\end{gathered}
$$

$\mathrm{N}_{0}=$ the number of rods

$$
\frac{\mathrm{R}_{\mathrm{s}}}{\mathrm{R}_{1}}=\frac{\sqrt{\frac{\mathrm{L}_{\mathrm{R}}}{\mathrm{r}}\left[\left(\frac{1}{2}\right)^{3}+\left(\frac{\mathrm{L}_{\mathrm{R}}}{\mathrm{L}_{\mathrm{R}}+\frac{\mathrm{r}}{2}}\right)^{3}\right]^{\frac{1}{3}}}}{2 \pi \mathrm{g}_{0}}
$$

If $\mathrm{h} \angle 1+\mathrm{h}_{\mathrm{o}}$

$$
\phi=\frac{\frac{1}{2 \pi}\left(\ln \frac{1}{1-\mathrm{K}}\right)}{\sqrt{\left(\frac{\mathrm{N}_{\mathrm{o}}}{\mathrm{F}}-1\right)^{2}\left(\frac{1+\mathrm{h}_{\mathrm{o}}}{\mathrm{h}}\right)^{2}+1}} \text { and }
$$

if $h>1+h_{o}$

$$
\phi=\frac{\frac{1}{2 \pi}\left(\ln \frac{1}{1-\mathrm{K}}\right)}{\sqrt{\left(\frac{\mathrm{N}_{\mathrm{o}}}{\mathrm{F}}-1\right)^{2}+1}}
$$

and the multiple reflections of the two-layer earth effectively changes the $\mathrm{F}$ factor of $\mathrm{N}_{\mathrm{o}}$ rods (Eq. 10) changes to $F_{o}$ in the two layers earth $F_{o}=\left.F\right|_{1 \rightarrow \frac{1}{1-0.9 \mathrm{~K}}}$, where the arrow means the replacement of $L_{R}$ by $\frac{\mathrm{L}_{\mathrm{R}}}{1-0.9 \mathrm{~K}}$ where $\mathrm{K}$ can be calculated using Eq. (2).

The calculated earth resistance values using the formulas from Chow et al. ${ }^{[2]}$ and together with its measured values are presented in Table 3 .

As can be shown from Table 2 and as expected that the earth resistance values obtained for site 1 is the lowest since it has the lowest soil resistivity values. Also, as expected the resistance values for the 4 rods are the lowest, since it has the largest surface area.

\section{MEASUREMENTS OF EARTH RESISTANCE VALUES}

Even though many literatures have published the work on the earth resistance calculations, it is still important to obtain the earth resistance by the measurements at field sites. In general, the earth resistance measurements are made in order, i) to determine the actual resistance of the ground connections, ii) as a check on calculations, iii) to determine the rise in ground potential and its variation throughout an area, that results from ground fault current in a power system, iv) to determine the suitability of a grounding connection for lightning protection and the suitability of a grounding connection for radio-frequency transmission at a transmitter, v) to obtain data necessary for the design of protection for buildings, the equipment therein and any personnel that may be involved.

In this study, the most common earth resistance measurement, which is a Fall-of-Potential method, is adopted. It would be expected that little discrepancies between the calculated and measured earth resistance values, which could be due to many factors such as; inadequacy of the analytical equations used in the resistance, inaccurate calculations due to changes in the soil conditions, insufficient extent of the resistivity survey, inadequacy of the instrumentation used and presence in the soil of adjacent metallic buried 
structures and ground wires which may divert a substantial amount of the test current. However, in this study, at each field site and configuration, the experiments were conducted at least twice to double check the measurements. From the testing, it was found that the results for both experiments are found to give consistent results.

As can be shown in Table 3, the percentage difference between the calculated and measured earth resistance for each earthing system is found to be below $10 \%$. The close results between the calculated and measured shows that the formulas developed by the previous authors ${ }^{[2]}$ can be adopted to calculate for the earth resistance values at preliminary design. Also, the interpretation of soil resistivity values into 2 layers may be adequate to obtain for the resistance values of earthing systems.

\section{LIST OF SYMBOLS}

$\rho: \quad$ Soil resistivity for uniform soil $(\Omega \mathrm{m})$

a: $\quad$ Probe spacing $(\mathrm{m})$

$\mathrm{R}: \quad$ Earth resistance $(\Omega)$

$\mathrm{K}$ : Reflection coefficient

$\rho_{1}$ : Resistivity of the first layer of the 2 layers soil $(\Omega \mathrm{m})$

$\rho_{2}$ : Resistivity of the second layer of the 2 layers soil $(\Omega \mathrm{m})$

$\mathrm{F}_{\mathrm{g}}$ : Minimisation function.

$\rho_{\alpha \mathrm{i}}^{\mathrm{m}}$ : Soil resistivity at $i^{\text {th }}$ measurement, where the distance between the sequential probes is $\alpha \mathrm{i}$

$\alpha i$ : Distance between the sequential probes (m)

$\rho_{\alpha \mathrm{i}}^{\mathrm{c}}$ : Computed value of the soil resistivity for the same distance $(\Omega \mathrm{m})$

$\mathrm{N}$ : Number of layer of earth model

$\mathrm{n}$ : Number of iterations

h: Thickness of the first layer (m)

$\mathrm{h}_{\mathrm{o}}$ : Grid sunken depth below earth surface $(\mathrm{m})$

$\mathrm{R}_{\mathrm{t}}$ : $\quad$ Rodbed resistance $(\Omega)$

$\mathrm{L}_{\mathrm{R}}$ : Length of driven $\operatorname{rod}(\mathrm{m})$

$\mathrm{N}_{0}$ : Number of rods

$\alpha$ : $\quad$ Radius of driven rod

$\mathrm{d}$ : Diameter of the rod $(\mathrm{m})$

\section{ABBREVIATIONS}

ANSI: American National Standard Institute

IEEE: Institute of Electrical and Electronic Engineers Std: $\quad$ Standard

\section{CONCLUSIONS}

In this research, the calculated and measured earth resistance values were obtained for 9 earthing systems.
The wenner method is used to obtain the resistivity values at 3 field sites. The resistivity data is interpreted into two layers earth using the master curves and GA, where the results are found to be close. The results are then applied into the formulas as in the literature ${ }^{[2]}$ to obtain the earth resistance values for 3 types of simple earthing systems, 2, 3 and 4 rods for each site. The measurement of earth resistance values is conducted for each earthing systems using the Fall-of-Potential method. Close results were obtained between the measured and calculated earth resistance values. The similarity in all the results proved that the measurement techniques and formulas adopted can be used to obtain the earth resistance values using the two-layered soil. Also, the interpretation of soil resistivity values into 2 layers may be adequate to obtain for the earthing systems.

\section{REFERENCES}

1. Nahman, J. and V.B. Djordjevic, 1996. Resistance to ground of combined grid-multiple rods electrodes. IEEE Trans. Power Delivery, 11 (3): 1337-1342.

2. Chow, Y.L., M.M. Elsherbiny and M.M.A. Salama1996. Resistance formulas of grounding systems in two-layer earth. IEEE Trans. Power Delivery, 11 (3): 1330-1336.

3. Gonos, I.F. and I.A. Stathopulos, 2005. Estimation of multilayer soil parameters using genetic algorithms. IEEE Trans. Power Delivery, 20 (1) 100-106.

4. Dawalibi, F. and C.J. Blattner, 1984. Earth resistivity measurement interpretation techniques. IEEE Trans. Power Delivery, PAS-103 (2): 374-382.

5. Dwight, H.B., 1936. Calculation of resistances to ground. AIEE Transactions, pp: 1319-1328.

6. del Alamo, J.L., 1993. A comparison among eight different techniques to achieve an optimum estimation of electrical grounding parameters in two-layered earth. IEEE Trans. Power Delivery, 8 (4): 1890-1898.

7. Orellana, E. and H.M. Mooney, 1996. Master Tables and Curves for Vertical Electrical Sounding (VES) Over Layered Structures. Madrid Interciecia.

8. ANSI/IEEE Std, 80-2000. IEEE Guide for Safety in AC Substation Grounding.

9. ANSI/IEEE Std, 81-1983. IEEE Guide for Measuring Earth Resistivity. Ground Impedance and Earth Surface Potentials of a Ground System.

10. ANSI/IEEE Std, 142-1991. IEEE Recommended Practice for Grounding Industrial and Commercial Power Systems. 